\title{
Implementing an Ebola Vaccine Study — Sierra Leone
}

\author{
Marc-Alain Widdowson, VetMB ${ }^{1}$ \\ Stephanie J. Schrag, $\mathrm{PhD}^{1}$ \\ Rosalind J. Carter, $\mathrm{PhD}^{1}$ \\ Wendy Carr, $\mathrm{PhD}^{1}$ \\ Jennifer Legardy-Williams, MPH ${ }^{1}$ \\ Laura Gibson, $\mathrm{MPH}^{2}$ \\ Durodami R. Lisk, $\mathrm{MBBS}^{3}$ \\ Mohamed I. Jalloh, MBChB ${ }^{4}$ \\ Donald A. Bash-Taqi, MBBS, MMed $^{3}$ \\ Samuel A. Sheku Kargbo, MD, DMed ${ }^{5}$ \\ Ayesha Idriss, $\mathrm{MSc}^{3}$ \\ Gibrilla F. Deen, $\mathrm{MD}^{3}$ \\ James B.W. Russell, MBChB 3 \\ Wendi McDonald, $\mathrm{RN}^{1}$ \\ Alison P. Albert, $\mathrm{MPH}^{1}$ \\ Michelle Basket ${ }^{1}$ \\ Amy Callis, $\mathrm{MPH}^{1}$ \\ Victoria M. Carter, $\mathrm{PhD}^{1}$ \\ Kelli R. Clifton Ogunsanya, $\mathrm{MHA}^{6}$ \\ Julianne Gee, $\mathrm{MPH}^{1}$ \\ Robert Pinner, $\mathrm{MD}^{1}$ \\ Barbara E. Mahon, MD \\ Susan T. Goldstein, $\mathrm{MD}^{1}$ \\ Jane F. Seward, MBBS ${ }^{1}$ \\ Mohamed Samai, MBChB, $\mathrm{PhD}^{3}$ \\ Anne Schuchat, $\mathrm{MD}^{1}$

\footnotetext{
${ }^{1}$ National Center for Immunization and Respiratory Diseases, CDC

${ }^{2}$ Conceptual Mindworks, Inc., San Antonio, Texas

4 Sierra Leone Police Medical Service, Freetown, Sierra Leone

${ }^{5}$ Ministry of Health and Sanitation, Freetown, Sierra Leone

${ }^{6}$ Pricewaterhouse Coopers, Atlanta, Georgia
} \\ ${ }^{3}$ College of Medicine and Allied Health Sciences, Freetown, Sierra Leone
}

Corresponding author: Marc-Alain Widdowson, National Center for Immunization and Respiratory Diseases, CDC. Telephone: 254-70-212-1124; E-mail: MWiddowson@cdc.gov.

\section{Summary}

In October 2014, the College of Medicine and Allied Health Sciences of the University of Sierra Leone, the Sierra Leone Ministry of Health and Sanitation, and CDC joined the global effort to accelerate assessment and availability of candidate Ebola vaccines and began planning for the Sierra Leone Trial to Introduce a Vaccine against Ebola (STRIVE). STRIVE was an individually randomized controlled phase IIIIII trial to evaluate efficacy, immunogenicity, and safety of the recombinant vesicular stomatitis virus Ebola vaccine (rVSV-ZEBOV). The study population was health care and frontline workers in select chiefdoms of the five most affected districts in Sierra Leone. Participants were randomized to receive a single intramuscular dose of rVSV-ZEBOV at enrollment or to receive a single intramuscular dose 18-24 weeks after enrollment. All participants were followed up monthly until 6 months after vaccination. Two substudies separately assessed detailed reactogenicity over 1 month and immunogenicity over 12 months. During the 5 months before the trial, STRIVE and partners built a research platform in Sierra Leone comprising participant follow-up sites, cold chain, reliable power supply, and vaccination clinics and hired and trained at least 350 national staff. Wide-ranging community outreach, informational sessions, and messaging were conducted before and during the trial to ensure full communication to the population of the study area regarding procedures and current knowledge about the trial vaccine. During April 9-August 15, 2015, STRIVE enrolled 8,673 participants, of whom 453 and 539 were also enrolled in the safety and immunogenicity substudies, respectively. As of April 28, 2016, no Ebola cases and no vaccine-related serious adverse events, which by regulatory definition include death, life-threatening illness, hospitalization or prolongation of hospitalization, or permanent disability, were reported in the study population. Although STRIVE will not produce an estimate of vaccine efficacy because of low case frequency as the epidemic was controlled, data on safety and immunogenicity will support decisions on licensure of rVSV-ZEBOV.

The activities summarized in this report would not have been possible without collaboration with many U.S. and international partners (http://www.cdc.gov/vhflebolaloutbreaks/2014-west-africalpartners.html). 


\section{Background to Trial Conception}

By August 2014, the unprecedented scope and exponential growth of the 2014-2016 Ebola virus disease (Ebola) epidemic in West Africa raised concern that control might be impossible without vaccination and prompted research and public health communities to accelerate development of Ebola vaccines. During September 4-5, 2014, the World Health Organization (WHO) convened advisors to review the most promising vaccine candidates and to consider the ethics of using investigational products in the expanding epidemic. As a result of this meeting, WHO called for "a coordinated effort by the international community to remove unnecessary obstacles" to accelerate evaluation and licensing of Ebola vaccines while acknowledging that for these to occur, an extraordinary pace of vaccine development, evaluation, and production would be needed (1). The National Institutes of Health (NIH) and the U.S. Army Medical Research Institute of Infectious Diseases were already engaged in human phase I (2) trials of Ebola vaccines, and an NIH partnership was establishing a phase II/III double-blind, randomized, placebo-controlled trial in Liberia of two of the leading Ebola vaccine candidates.

Since March 2014, CDC had been focused on the Ebola outbreak response, and in September 2014, the agency began to consider launching a second U.S. government-sponsored phase II/III Ebola vaccine trial in Sierra Leone. The rationale was to develop an alternative approach to a blinded, placebo-controlled trial that was potentially less complex and thus easier to implement in Sierra Leone, where government agencies were struggling to respond to a devastating epidemic, yet an approach that would still provide data on efficacy, immunogenicity, and safety for vaccine licensure. If the vaccine were efficacious, vaccination of a large number of trial participants also could protect persons at high risk and potentially help control the worsening outbreak. Two distinct approaches in different sites would also mitigate the risk that one approach might not be successful.

In October 2014, CDC established a partnership with Sierra Leone to conduct an Ebola vaccine clinical trial, while a WHO-led international consortium began planning an Ebola ring vaccination trial in Guinea. The CDC-Sierra Leone trial, subsequently named STRIVE (Sierra Leone Trial to Introduce a Vaccine against Ebola), was led by the College of Medicine and Allied Health Sciences (COMAHS) of the University of Sierra Leone, the Sierra Leone Ministry of Health and Sanitation (MoHS), and CDC. CDC sent technical staff in late October to Sierra Leone to work with COMAHS and MoHS leadership to start trial planning. During the initial conception, two further key principles were articulated: 1) the trial was not to detract from the main epidemic response and 2) the trial would contribute to longer-term capacity building and transfer of skills within Sierra Leone.

\section{Trial Design and Ethical Considerations}

Early data from Sierra Leone suggested that health care workers (HCWs) had a 100-fold higher risk for Ebola than the general community (3); therefore, the study population was selected to include all staff at health care facilities (i.e., clinical and nonclinical workers) and other Ebola frontline workers (e.g., surveillance, burial, and ambulance team members). Power calculations indicated that at least 67 Ebola cases were needed in the study population to detect a vaccine efficacy of $50 \%$, and facility censuses and disease rates calculated near the peak of the epidemic led STRIVE collaborators to initially target a population of 6,000 participants in the five most heavily affected of the 14 districts of Sierra Leone. The logistics of travel and vaccine transport on poor roads, especially in the rainy season, necessitated choosing, within the selected districts, centrally located chiefdoms with the highest numbers of HCWs and Ebola cases.

A modified stepped wedge design (4) was initially considered for the study: health facilities and teams of health care and frontline workers throughout the study area would each be randomized to receive vaccine at a specified time over a 6-month period until all staff in all facilities in the study area were offered vaccine. Ebola rates and adverse events would be compared at any one time between vaccinated and (up to that point) unvaccinated staff and facilities over the study period. However, several key logistic and methodologic limitations of this approach posed obstacles. First, the design required follow-up of the entire study population from the trial start; therefore, all staff in all facilities had to be enrolled before the first dose of vaccine could be administered. Second, once all staff in facilities were enrolled, very limited opportunity existed to expand the sample size, yet declining background rates of Ebola suggested this might be needed. Third, Ebola increasingly occurred in clusters as overall incidence declined; therefore, an imbalance of Ebola risk could easily occur between facilities with vaccinated staff and facilities with unvaccinated staff and lead to lower statistical power and unreliable results (5). Because of these limitations, STRIVE collaborators chose an individually randomized trial of health care and frontline workers assigned to different vaccination times. This approach would provide flexibility of implementation because staff in each facility could be enrolled independently from staff in other facilities (allowing for the possibility of increasing sample size easily), as well as more discrete units of randomization and greater statistical power. At screening and enrollment, participants were randomized to receive vaccine immediately (immediate vaccinees) or 18-24 weeks later (deferred vaccinees), and all were monitored monthly from enrollment until 6 months after 
vaccination for Ebola and for serious adverse events, which according to the regulatory definition involve hospitalization or prolongation of hospitalization, death, or reported lifethreatening illness or permanent disability (G). The STRIVE protocol was approved ( 7 ) by the Sierra Leone Ethics and Scientific Review Committee and the CDC Institutional Review Board (CDC-NCIRD-6689) and registered at https:// clinicaltrials.gov (identifier NCT02378753).

In early discussions with Sierra Leone partners when deaths from Ebola were highest, the use of a placebo was ruled out because of the logistic complexity of implementing a placebo and concerns that placebo recipients might feel protected against Ebola and put themselves at risk. The lack of placebo opened up the study to several biases. For instance, immediate vaccinees might be assigned to a higher risk duty or be less careful in using personal protective equipment (PPE) than deferred vaccinees. Immediate vaccinees also might be more likely than persons who had not yet been vaccinated to report adverse events possibly associated with the vaccine or seek care for illness, thus biasing potential safety signals especially for milder adverse events. Reporting of Ebola was considered less likely to be susceptible to bias because Ebola generally has a severe clinical picture and surveillance is comprehensive. To reduce bias, STRIVE staff emphasized to each participant that the level of protection afforded by the vaccine was unknown and therefore Ebola prevention behaviors should not be relaxed. Design elements were added to measure bias, such as questions about use of PPE or changes in duties. Nonetheless, these potential biases complicated the comparison of frequency of events between the immediate and deferred vaccinees (especially adverse events, because ultimately, no Ebola cases were reported in the study population).

In addition to the main study, STRIVE planned two substudies. The first was a safety substudy of 400 participants (200 vaccinated, 200 unvaccinated) at the start of the trial with follow-up for adverse events on days 1, 3, 7, 14, and 28 after enrollment. The second was an immunogenicity substudy of 500 participants enrolled during June-September 2015 with blood draws at day 0 , day 28 , month 6 , and once during months 9-12 after vaccination.

Because this clinical trial of an experimental live vaccine of unknown effectiveness and safety would be conducted in a population with high levels of poverty and low literacy in the midst of an Ebola epidemic, ethical issues were a foremost consideration. One concern was that fear of Ebola could lead to a skewed risk-benefit calculation by health care and frontline workers in their decision to receive a vaccine of unclear safety and efficacy. STRIVE staff also were aware that reimbursements for participation and free health care could further induce enrollment. Careful messaging about the uncertainty of protection afforded by the vaccine was used to prevent participants from undertaking tasks at work or in the community that could place them at greater risk for Ebola. To maintain the balance between immediate and deferred vaccine arms and the integrity of randomization, each site was provided with sealed allocation envelopes in a predetermined sequence. To ensure that participants correctly perceived the envelope sequence as entirely random, enrollees were asked to choose one of five envelopes next in sequence. These ethical and communication concerns were addressed with guidance from Sierra Leone STRIVE leadership and other partners. Active and transparent communication of risks and benefits to participants and the public continued throughout the trial as the risk-benefit balance changed with ebbing Ebola incidence.

STRIVE was also positioned to help the outbreak response with the shared priority of early identification and diagnosis of suspected Ebola cases through the continued monitoring of participants. One complication identified early in trial planning was that during the phase I trials the vaccine could cause fever, myalgia, and fatigue in the first day or two after administration. Recent vaccinees could have a mild vaccine reaction that met the definition of suspected Ebola and be referred to Ebola holding centers where they could be unnecessarily exposed to Ebola. Identification and treatment of true Ebola among vaccinees could not be substantially delayed, nor could associated public health responses (e.g., contact tracing) be impeded. After discussions with the response leadership in Sierra Leone, STRIVE leaders slightly modified the suspected case definition for trial participants for the first 48 hours after vaccine receipt to allow for a short delay in determining whether a person had suspected Ebola if that person was a recent vaccinee exhibiting only symptoms consistent with vaccination. ${ }^{*}$ Any vaccinees with Ebola exposure or exhibiting any Ebola symptoms that were inconsistent with vaccination at any time were immediately treated as having suspected Ebola.

\section{Vaccine Selection}

In late summer and early fall 2014, only limited data from nonhuman primate studies existed on the two leading vaccine

\footnotetext{
* Standard suspected Ebola case definition: Temperature $\geq 38^{\circ} \mathrm{C}\left(\geq 100.4^{\circ} \mathrm{F}\right)$ and three or more of the following symptoms: headache, loss of appetite, fatigue, muscle/joint pain, diarrhea, unusual bleeding, difficulty breathing, nausea, vomiting, abdominal pain, difficulty swallowing, or hiccups; OR illness after direct, unprotected Ebola contact or a breach in personal protective equipment in the past 21 days. Modified case definition applied to vaccine recipients in the first 48 hours after vaccination: same as for standard suspected Ebola case except that at least one symptom had to be one of the following symptoms not consistent with a vaccine reaction: diarrhea, unusual bleeding, difficulty breathing, nausea, vomiting, abdominal pain, difficulty swallowing, or hiccups.
} 
candidates poised to begin phase I trials in humans at that time. Both candidates used live recombinant virus vectors encoding the surface glycoprotein of the Ebola virus (EBOV). One was the replication-deficient recombinant chimpanzee adenovirus type-3 vectored vaccine (ChAd3-EBOV), developed by the National Institute of Allergy and Infectious Diseases of NIH and licensed for development to GlaxoSmithKline (GSK); the second was the replication-competent, recombinant vesicular stomatitis virus vectored vaccine (rVSV-ZEBOV) developed by the Public Health Agency of Canada, licensed to NewLink Genetics Corporation then later to Merck and Co., Inc. (Merck), for further development.

In October 2014, a report suggested that a single dose of ChAd3-EBOV would protect macaques against lethal challenge of 1,000 plaque-forming units of EBOV administered intramuscularly (8). Although humoral and cell-mediated responses specific to the EBOV glycoprotein were elicited by the vaccine, protection seemed of short duration because deaths increased among macaques challenged at 10 months after initial vaccination. A second vaccination (a heterologous boost) of modified vaccinia Ankara with EBOV glycoprotein (MVAEBOV), given a month after initial vaccination with ChAd3EBOV, appeared more likely to provide durable protection (8). Challenge studies of rVSV-ZEBOV vaccine in nonhuman primates also provided evidence of protection and humoral immune response $(9,10)$. Data on longevity of protection were not available for rVSV with EBOV glycoprotein, only for a vesicular stomatitis virus recombinant with Marburg virus, which, although related, is less virulent and therefore could not be used as proxy for Ebola virus (11).

By January 2015, some of the first human phase I data on immunogenicity and safety in small groups of healthy adults became available for both vaccines. Early results on humoral and cell-mediated responses of $\mathrm{ChAd} 3$-EBOV were promising overall, although somewhat mixed $(12,13)$, and similarly encouraging humoral responses to rVSV-ZEBOV were found at day 28 after vaccination (14). These small studies of both vaccines had not detected any safety issues, but in midDecember 2014, a phase I study under way in Switzerland that used rVSV-ZEBOV was paused to assess episodes of reported arthritis that began during the second week after vaccination. In early January 2015, the study was resumed at a lower dose of vaccine (15). Investigators of other phase I studies in the United States examined their data but did not initially detect similar adverse events (14), although an association was detected later in some other trials also.

In early 2015, intensive public health control measures led to decreasing intensity of the Ebola epidemic in Sierra Leone, although the situation remained unpredictable. To provide useful data on efficacy for possible vaccine licensure, starting the trial as soon as possible was essential. Therefore, selection of a vaccine and filing by CDC (as trial sponsor) of an investigational new drug (IND) application became urgent. Although the use of a priming vaccination with ChAd3-EBOV boosted with a second vaccination with MVA-EBOV generally was seen as the best opportunity to provide durable protection with ChAd3-EBOV, this strategy presented several critical disadvantages. These included the need for longer follow-up (because of the interval between doses), the difficulty in attributing safety issues to two different products, the need for more space and staff to follow up and vaccinate participants twice, the need for more cold chain capacity, and the lack of human data on MVA-EBOV submitted to the Food and Drug Administration for evaluation in early 2015. Statistical power calculations made clear that comparing two vaccines would need an untenably large trial with $\mathrm{HCW}$, thus leaving the choice between a single-dose regimen of ChAd3-EBOV or rVSV-ZEBOV. An additional variable was that in early 2015, GSK and Merck were still examining data from dose-ranging studies to ascertain the optimum vaccine dose for trials and licensure.

STRIVE leadership convened expert groups that advised that, as a live replication-competent vaccine, a single dose of rVSV-ZEBOV was more likely to provide durable and rapid protection than ChAd3-EBOV. Moreover, ChAd3-EBOV was needed for other trials, and it was uncertain in January 2015 whether sufficient doses of GSK's final formulation of the vaccine would be available in time for STRIVE's launch. For these reasons, in late January 2015, STRIVE leadership at COMAHS, MoHS, and CDC selected a single dose of rVSV-ZEBOV at the manufacturer-recommended dose of $2 \times 10^{7}$ plaque-forming units $/ \mathrm{mL}$ for the trial. At that time, $<100$ persons had received this or a higher dose of this vaccine in clinical trials. Merck and Newlink Genetics Corporation provided and shipped the vaccine doses necessary for the trial.

\section{Establishing the Trial Platform}

Trials conducted under IND regulations require a high level of rigor in methods and implementation and continuous monitoring and documentation for the data to be useful to the licensing pathway. Sierra Leone is still recovering from a civil war that ended in 2002, leaving a fragile infrastructure and limited clinical research capacity exacerbated by a paucity of physicians in the country (approximately 150 for a country of 6 million persons in 2010 [16]). In addition, the fundamental requirements for the trial (i.e., clinics for vaccination, office space for data management, a reliably powered and mobile cold chain that could keep the vaccine at the required $-80^{\circ} \mathrm{C}$ 
$\left[-112^{\circ} \mathrm{F}\right]$, Internet access, and laboratory capacity) were either not available or adequate in Sierra Leone.

To meet the unprecedented challenge of sponsoring and leading an IND trial on short notice in this demanding context, STRIVE leadership at CDC began to identify relevant expertise throughout the agency, without detracting from the response. Insurance and medical evacuation considerations largely prevented use of nongovernment staff; therefore, efforts were initiated to hire external staff into U.S. government positions specifically for longer-term deployment. CDC also arranged with various partners to support the logistic needs and preparatory work for the trial and finding solutions to the many challenges (Table 1). The U.S. Department of Health and Human Services' Biomedical and Advanced Research and Development Authority committed expert staff and used existing mechanisms for clinical trials to fund and establish contracts to secure clinical monitoring, safety monitoring, data management, and cold chain assistance through multiple contract research organizations. The CDC Foundation raised donor funds that could be immediately used for early demands, such as infrastructure building, supplies, and hiring staff by an in-country nongovernment agency, eHealth Africa. WHO assessed the cold chain capacity in country and provided $-80^{\circ} \mathrm{C}$ $\left(-112^{\circ} \mathrm{F}\right)$ freezers necessary to store and transport the vaccine. Intellectual Ventures provided units of the newly developed Arktek, a system that uses alcohol-based refrigerants (phasechange materials) that can maintain $-80^{\circ} \mathrm{C}$ temperatures for several days with no power, enabling vaccine transport and short-term storage at district enrollment sites (17).

Provision of power, Internet, and even water for basic use proved challenging throughout the trial. Developing a reliable source of power for the cold chain storage depots and offices for data entry required establishment of several combinations of backup generators, solar power, and battery systems that were supported by international engineering expertise from the German Federal Agency for Technical Relief.

Early on, in response to the epidemic, COMAHS (medical, nursing, and pharmacy schools) closed so as not to put students and staff at increased risk for Ebola during training; thus these students and staff were able to work for the trial. However, very few had prior training in Good Clinical Practice and the precepts of human subject research required for a trial under IND regulations. Therefore, in March 2015, at least 350 staff were trained on site by CDC, COMAHS, MoHS, and two of the contract research organizations, FHI360 and Emmes Corporation. Retraining continued as the trial progressed and procedural issues were identified.

\section{Communication}

During the epidemic, the highly charged social environment made the conduct of a large trial of an IND with very limited data from previous human trials particularly delicate. STRIVE created a communication plan to 1) increase awareness and confidence in STRIVE among stakeholders and opinion leaders; 2) educate potential study participants on the risks and benefits of trial participation, informed consent, and confidentiality; 3) anticipate and prepare responses to public rumors, misinformation, controversy, or questions about the trial; and 4) ensure clear, consistent messages among all study staff and partners. In December 2014, formative research, including in-depth interviews and focus groups, was conducted with the general public, public health leaders, and groups eligible for vaccination to understand their knowledge, attitudes, and beliefs about Ebola vaccines and the vaccine trial.

STRIVE leadership was committed to transparency about the proposed design and to sharing all data available on the vaccine. Leaders from COMAHS and MoHS conducted

TABLE 1. Challenges and solutions of implementing Sierra Leone Trial to Introduce a Vaccine against Ebola

\begin{tabular}{|c|c|}
\hline Challenge & Solution \\
\hline $\begin{array}{l}\text { No }-80^{\circ} \mathrm{C}\left(-112^{\circ} \mathrm{F}\right) \text { freezers or method of transport at } \\
-80^{\circ} \mathrm{C}\left(-112^{\circ} \mathrm{F}\right)\end{array}$ & Purchase and international shipping of freezers; phase change material transporters (Arktek) \\
\hline No appropriate space for enrollment and vaccination & Identify, negotiate use, and renovate some facilities \\
\hline No space for data entry and management & Build and renovate facilities \\
\hline No reliable Internet for data entry, storage, and transmission & Installation of satellite routed Internet and wireless capacity \\
\hline $\begin{array}{l}\text { No reliable power for cold chain, laboratory, and participant } \\
\text { follow-up sites }\end{array}$ & Installation of generators, solar panels, and backup batteries \\
\hline $\begin{array}{l}\text { Health status of population unknown; poor and dispersed } \\
\text { health care access }\end{array}$ & Establish free medical care; provide supplies to upgrade intensive care unit at referral hospital \\
\hline $\begin{array}{l}\text { Misinformation and misconceptions on vaccines and the } \\
\text { motives of the trial organizers }\end{array}$ & Focus groups, key informant interviews, informational sessions, extensive communication materials \\
\hline Relevant supplies limited in country & Procure and ship supplies internationally \\
\hline $\begin{array}{l}\text { No basic equipment (e.g., centrifuges) in country for } \\
\text { serology study }\end{array}$ & Procure and ship equipment internationally \\
\hline No staff GCP training; inexperienced research staff & Conduct large scale, in person training; repeated retraining on operating procedures \\
\hline
\end{tabular}

Abbreviations: GCP = Good Clinical Practice; STRIVE = Sierra Leone Trial to Introduce a Vaccine against Ebola. 
numerous outreach sessions with tribal and religious leaders of selected chiefdoms, district health leaders, and professional organizations to explain the proposed trial, to understand concerns, and to garner support and feedback. Study team members also met with leaders of every eligible health facility. This outreach established relationships between STRIVE staff and the health care community in the study areas, which enabled continuous dialogue on the trial. In February 2015, STRIVE leadership presented the trial plans to the full government and to the news media.

Beginning in March 2015, the STRIVE team held 175 informational sessions in facilities in the areas where the clinical trial was to take place to introduce it to potential participants using materials developed as a result of the formative research. At enrollment, participants were provided with similar materials on all aspects of the trial and an informed consent form. Participants also had 24-hour access to a hotline with trained staff to answer questions about the trial and procedures.

\section{Trial Status}

Seven trial enrollment sites were set up in five Sierra Leone districts (one in each of Western Urban, Western Rural, Bombali, and Tonkolili districts and three in Port Loko district). Enrollment and vaccinations began on April 9, 2015, in the Western Rural location; the other six sites were opened during the subsequent 11 weeks and remained open for varying periods, depending on the estimated size of the local population of eligible frontline workers and HCWs (Figure 1). Enrollment ended on August 15, 2015 , and sites began reopening to vaccinate the deferred group on September 19, 2015. Vaccination was completed on December 12, 2015, and as of April 28, 2016, on the basis of preliminary data, 8,673 participants were enrolled and 8,016 vaccinated, of whom 3,826 received deferred vaccination (Figure 2).

A total of 539 participants enrolled in the immunogenicity study. Of these, 509 provided baseline blood samples, of whom $466(92 \%)$ provided a day-28 blood sample and 411 (81\%)

\section{FIGURE 1. Study sites and enrollment through October 2015 for the Sierra Leone Trial to Introduce a Vaccine against Ebola}

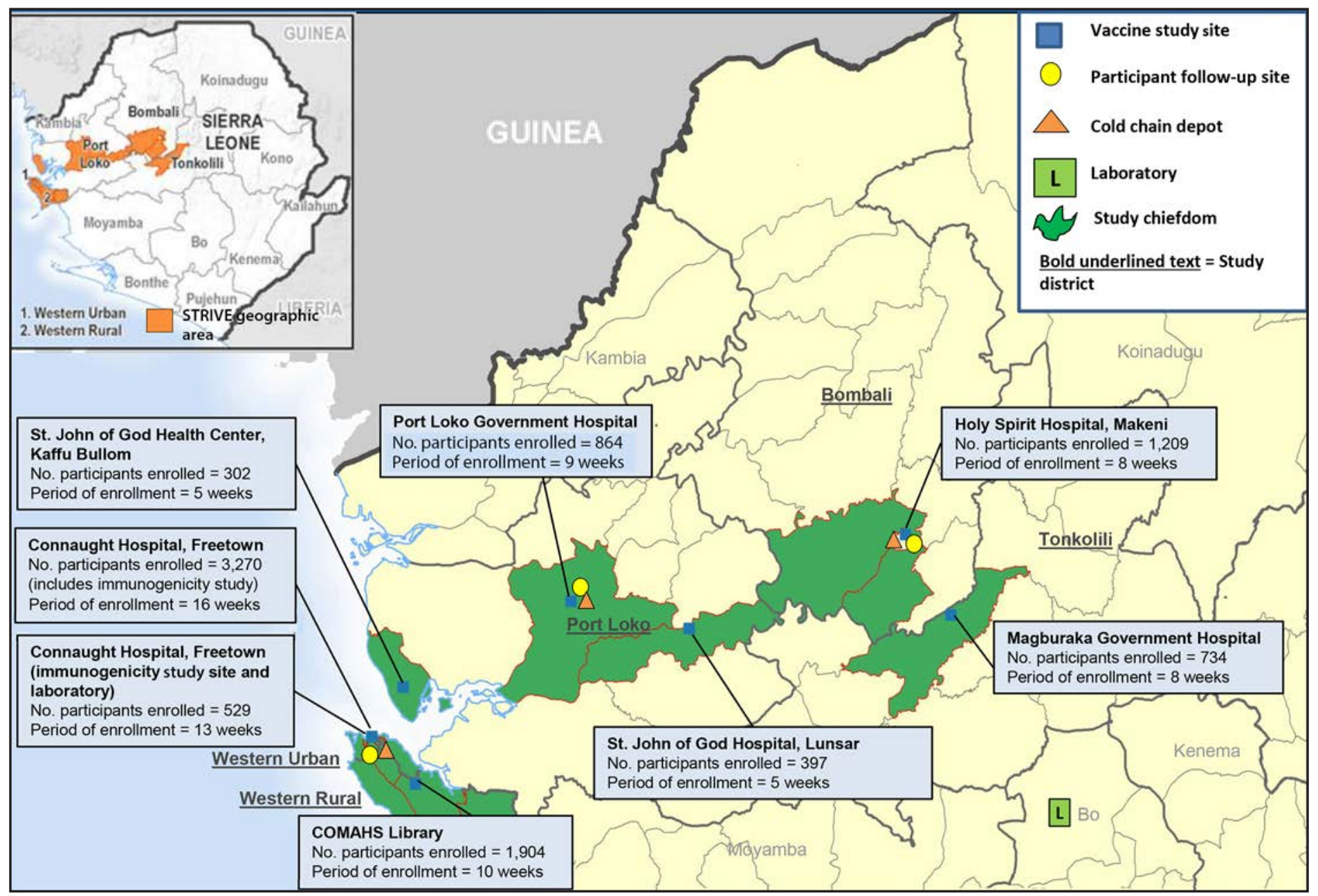

Abbreviations: COMAHS = College of Medicine and Allied Health Sciences, University of Sierra Leone; STRIVE = Sierra Leone Trial to Introduce a Vaccine against Ebola. 
FIGURE 2. Timeline of Sierra Leone Trial to Introduce a Vaccine against Ebola enrollment and implementation, by number of cases, enrollees, and month — seven sites, ${ }^{*}$ Sierra Leone, July 2014-December 2015

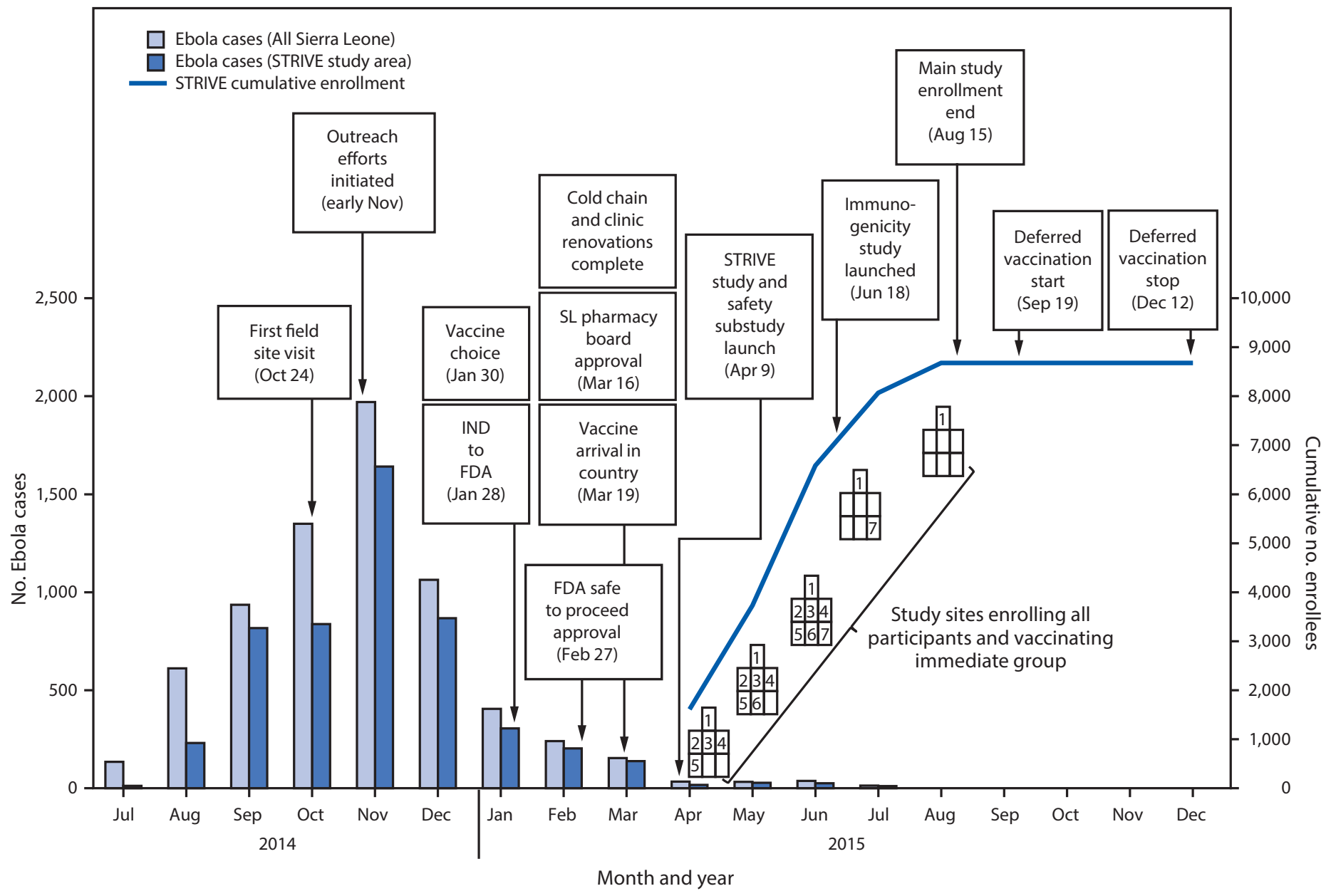

Source: Sierra Leone National Emergency Response Center situational reports.

Abbreviations: Ebola = Ebola virus disease; FDA = Food and Drug Administration; IND = investigational new drug application; SL = Sierra Leone; STRIVE = Sierra Leone Trial to Introduce a Vaccine against Ebola.

* Active study sites (indicated by numbered boxes): 1 = Connaught Hospital (Western Urban district); 2 = College of Medicine and Allied Health Sciences Library, University of Sierra Leone (Western Rural district); $3=$ Port Loko Government Hospital (Port Loko district); $4=$ Holy Spirit Hospital (Bombali district); $5=$ Magburaka Government Hospital (Tonkolili district); 6 = St. John of God Hospital, Lunsar (Port Loko district); 7 = St. John of God Health Center, Kaffu Bullom (Port Loko district).

provided a 6-month blood sample. The blood draws for months 9-12 after vaccination began in June 2016. The safety substudy enrolled 453 participants (227 immediate vaccinees and 226 deferred vaccinees) in April 2015. As of April 28, 2016, a total of 64 participants had illnesses that were investigated as suspected Ebola, of whom 60 provided specimens for testing, but none were confirmed as Ebola. No serious adverse events related to vaccination have been reported; the data from the safety substudy are generally consistent with data found in phase I trials of the vaccine, and no association of vaccine with arthritis has been noted.

\section{The Future}

On August 3, 2015, the WHO-led consortium conducting the ring vaccination trial in Guinea that used rVSV-ZEBOV (Ebola ça Suffit!) reported interim vaccine efficacy results of 100\% (95\% confidence interval: 75\%-100\%) and only one serious adverse event (a postvaccinal fever that resolved) (18). The trial design was one in which contacts and contacts-ofcontacts of index cases (rings) would be vaccinated immediately or 3 weeks after the report of an index case. With these encouraging results, the ring trial expanded to Sierra Leone in September 2015 with the change that all rings receive vaccine immediately. As of April 28, 2016, ring vaccination has been 
conducted in response to three cases. Regulatory agencies will be evaluating rVSV-ZEBOV and other Ebola vaccines for licensure as more data on efficacy, immunogenicity, and safety become available. Until that time, access to candidate vaccines requires enrollment in a clinical trial.

On November 7, 2015, WHO declared the end of EBOV transmission in Sierra Leone. In January 2016, however, two new cases were reported in Sierra Leone. Several factors contribute to a persistent risk for new Ebola cases and clusters: 1) an increase in standard patient care and handling with reduced protection; 2) increases in population movements, including introduction from neighboring countries; and 3) the persistence of viable EBOV in recovered patients, potentially resulting in recrudescence of illness or transmission through semen (19). Ongoing vigilance will be necessary, possibly in addition to a variety of vaccine approaches, to extinguish transmission altogether in the region. Gavi, the Vaccine Alliance has committed US $\$ 300$ million to purchase a licensed vaccine and US $\$ 45$ million for costs of vaccination campaigns (20).

Although STRIVE will not be able to measure vaccine efficacy because of the absence of reported EBOV transmission in HCWs during the study period, STRIVE will provide key data on safety, reactogenicity, and immunogenicity to inform licensure. The impact and accomplishments also extend beyond contributing data needed for vaccine licensure and support any vaccine deployment. These include lessons on acceptance of the vaccine; improved cold chain infrastructure, including various new technologies; capacity for basic laboratory work and data management; communication expertise; and staff experienced with this vaccine (Table 2). A longer-term benefit is a newly forged relationship between institutions in Sierra Leone and
CDC, a relationship that has strengthened capacity in Sierra Leone to better and more rapidly investigate and control future infectious disease outbreaks and prevent any repeat of an Ebola epidemic of this scale.

\section{Acknowledgments}

Members of all implementing partners and STRIVE staff; Nancy Messonnier for efforts to set up STRIVE in the first several months; CDC Ebola response staff in Atlanta and in affected countries; all the study participants; the STRIVE Vaccine Research Group.

\section{Disclosure of Relationship}

The STRIVE study authors disclose that they have no financial conflicts of interest.

\section{References}

1. World Health Organization. Potential Ebola therapies and vaccines. Interim guidance 2014. http://apps.who.int/iris/bitstream/10665/137590/1/ WHO_EVD_HIS_EMP_14.1_eng.pdf

2. National Library of Medicine. FAQ. ClinicalTrials.gov—clinical trial phases. https://www.nlm.nih.gov/services/ctphases.html

3. Kilmarx PH, Clarke KR, Dietz PM, et al. Ebola virus disease in health care workers-Sierra Leone, 2014. MMWR Morb Mortal Wkly Rep 2014;63:1168-71.

4. Hemming K, Haines TP, Chilton PJ, Girling AJ, Lilford RJ. The stepped wedge cluster randomised trial: rationale, design, analysis, and reporting. BMJ 2015;350:h391. http://dx.doi.org/10.1136/bmj.h391

5. Bellan SE, Pulliam JR, Pearson CA, et al. Statistical power and validity of Ebola vaccine trials in Sierra Leone: a simulation study of trial design and analysis. Lancet Infect Dis 2015;15:703-10. http://dx.doi. org/10.1016/S1473-3099(15)70139-8

6. Food and Drug Administration. 21 CFR Part 600.80. Postmarketing reporting of adverse experiences. Federal Register 1997;62:52252-3.

7. CDC. Sierra Leone Trial to Introduce a Vaccine against Ebola (STRIVE) Q\&A. http://www.cdc.gov/vhf/ebola/strive/qa.html

TABLE 2. Present and future impact and accomplishments of Sierra Leone Trial to Introduce a Vaccine against Ebola

\begin{tabular}{|c|c|}
\hline Impact & Accomplishments \\
\hline Contribution to decision on licensing of Ebola vaccine & $\begin{array}{l}\text { Generated data on } \\
\text { - vaccine safety (serious adverse events*) for approximately 8,000 vaccinees; } \\
\text { - vaccine safety (detailed reactogenicity) for participants randomized to either receive vaccine } \\
\text { immediately (approximately } 200 \text { ) at enrollment or } 18-24 \text { weeks later (approximately 200); } \\
\text { - vaccine immunogenicity among approximately } 500 \text { vaccinees; and } \\
\text { - duration of humoral response among } 300-500 \text { vaccinees. }\end{array}$ \\
\hline Supported rollout of licensed Ebola vaccines & $\begin{array}{l}\text { Generated information about } \\
\text { - vaccine acceptance in Sierra Leone communities, and } \\
\text { - feasibility and logistics of use of Ebola vaccine with challenging storage and handling requirements. } \\
\text { Developed communication plans and materials developed for trial built on research in community. } \\
\text { Built cold chain capacity and power solutions to hold and transport vaccine at }-80^{\circ} \mathrm{C}\left(-112^{\circ} \mathrm{F}\right) \text {. }\end{array}$ \\
\hline Strengthened capacity to conduct public health research & $\begin{array}{l}\text { Trained } \\
\text { - at least } 350 \text { national staff in GCP and human subjects research, and } \\
\text { - four national staff in laboratory practice. } \\
\text { Built conference center for use as participant follow-up site. } \\
\text { Developed foundation for long-term relationship between COMAHS and CDC. }\end{array}$ \\
\hline Prevented Ebola infections & $\begin{array}{l}\text { Vaccinated approximately } 8,000 \text { high-risk persons with vaccine that is likely effective during period } \\
\text { when EBOV was still actively circulating. }\end{array}$ \\
\hline
\end{tabular}

Abbreviations: COMAHS = College of Medicine and Allied Health Sciences, University of Sierra Leone; Ebola = Ebola virus disease; EBOV = Ebola virus; GCP = Good Clinical Practice.

${ }^{*}$ According to the regulatory definition, serious adverse events involve hospitalization or prolongation of hospitalization, death, or reported life-threatening illness or permanent disability. Food and Drug Administration 21 CFR Part 600.80. Postmarketing reporting of adverse experiences. Federal Register 1991;62;52252-3. 
8. Stanley DA, Honko AN, Asiedu C, et al. Chimpanzee adenovirus vaccine generates acute and durable protective immunity against Ebolavirus challenge. Nat Med 2014;20:1126-9.

9. Jones SM, Feldmann H, Ströher U, et al. Live attenuated recombinant vaccine protects nonhuman primates against Ebola and Marburg viruses. Nat Med 2005;11:786-90. http://dx.doi.org/10.1038/nm1258

10. Marzi A, Engelmann F, Feldmann F, et al. Antibodies are necessary for rVSV/ ZEBOV-GP-mediated protection against lethal Ebola virus challenge in nonhuman primates. Proc Natl Acad Sci U S A 2013;110:1893-8. http:// dx.doi.org/10.1073/pnas.1209591110

11. Mire CE, Geisbert JB, Agans KN, et al. Durability of a vesicular stomatitis virus-based Marburg virus vaccine in nonhuman primates. PLoS One 2014;9:e94355. http://dx.doi.org/10.1371/journal.pone.0094355

12. Ledgerwood JE, Sullivan NJ, Graham BS. Chimpanzee adenovirus vector Ebola vaccine-preliminary report. N Engl J Med 2015;373:776. http:// dx.doi.org/10.1056/NEJMc1505499

13. Rampling T, Ewer K, Bowyer G, et al. A monovalent chimpanzee adenovirus Ebola vaccine_-preliminary report. N Engl J Med 2015 [ahead of print]. http://dx.doi.org/10.1056/NEJMoa1411627

14. Regules JA, Beigel JH, Paolino KM, et al. A recombinant vesicular stomatitis virus Ebola vaccine-preliminary report. N Engl J Med 2015 [ahead of print]. http://dx.doi.org/10.1056/NEJMoa1414216
15. Agnandji ST, Huttner A, Zinser ME, et al. Phase 1 trials of rVSV Ebola vaccine in Africa and Europe-preliminary report. N Engl J Med 2015 [ahead of print]. http://dx.doi.org/10.1056/NEJMoa1502924

16. World Health Organization. Health workforce: density of physicians 2015. http://gamapserver.who.int/gho/interactive_charts/health_ workforce/PhysiciansDensity_Total/atlas.html

17. ModifiedArktek to supportEbolavaccinetrials. http://www.intellectualventureslab. $\mathrm{com} /$ invent/modified-arktek-to-support-ebola-vaccine-trials

18. Henao-Restrepo AM, Longini IM, Egger M, et al. Efficacy and effectiveness of an rVSV-vectored vaccine expressing Ebola surface glycoprotein: interim results from the Guinea ring vaccination clusterrandomised trial. Lancet 2015;386:857-66. http://dx.doi.org/10.1016/ S0140-6736(15)61117-5

19. Christie A, Davies-Wayne GJ, Cordier-Lassalle T, et al. Possible sexual transmission of Ebola virus-Liberia, 2015. MMWR Morb Mortal Wkly Rep 2015;64:479-81. Erratum in: MMWR Morb Mortal Wkly Rep 2015;64:1180.

20. Gavi. Gavi commits to purchasing Ebola vaccine for affected countries. 2014. http://www.gavi.org/Library/News/Press-releases/2014/ Gavi-commits-to-purchasing-ebola-vaccine-for-affected-countries/ 



The Morbidity and Mortality Weekly Report (MMWR) Series is prepared by the Centers for Disease Control and Prevention (CDC) and is available free of charge in electronic format. To receive an electronic copy each week, visit MMWR's free subscription page at http://www.cdc.gov/mmwr/mmwrsubscribe.html. Paper copy subscriptions are available through the Superintendent of Documents, U.S. Government Printing Office, Washington, DC 20402; telephone 202-512-1800

Readers who have difficulty accessing this PDF file may access the HTML file at http://www.cdc.gov/mmwr/volumes/65/su/su6503a1.htm?s_ cid=su6503a1_w. Address all inquiries about the $M M W R$ Series, including material to be considered for publication, to Executive Editor, $M M W R$ Series, Mailstop E-90, CDC, 1600 Clifton Rd., N.E., Atlanta, GA 30329-4027 or to mmwrq@cdc.gov.

All material in the MMWR Series is in the public domain and may be used and reprinted without permission; citation as to source, however, is appreciated. Use of trade names and commercial sources is for identification only and does not imply endorsement by the U.S. Department of Health and Human Services.

References to non-CDC sites on the Internet are provided as a service to $M M W R$ readers and do not constitute or imply endorsement of these organizations or their programs by CDC or the U.S. Department of Health and Human Services. CDC is not responsible for the content of these sites. URL addresses listed in $M M W R$ were current as of the date of publication.

ISSN: 2380-8950 (Print) 